\title{
(Política do) dizer sobre a língua na ótica do mercado da divulgação*
}

Larissa Montagner Cervo ${ }^{* *}$

\begin{abstract}
Resumo: Neste artigo, objetivamos apresentar a reflexão que produzimos na nossa dissertação de mestrado intitulada Do lugar do linguista e da língua como objeto de divulgação. Sob a ótica da língua como um objeto de divulgação, numa perspectiva que desliza para a sua significação como objeto de mercado, trabalhamos com textos de divulgação de autoria de linguistas buscando observar como sujeitos da ciência 'publicizam' o conhecimento sobre a língua, tomando o cuidado de questionarem e confrontarem ou apenas reforçando sentidos já instituídos e que legitimam processos de inclusão/exclusão também já instalados (Orlandi, 2006).
\end{abstract}

Palavras-chave: Língua; Discurso de divulgação científica; Linguista.

O problema de pesquisa para o qual voltamo-nos, em nossa dissertação de mestrado, a língua enquanto um objeto de divulgação, foi problematizado sob a ótica de um objeto que se constitui pelo discurso de divulgação científica e que significa no imaginário social como um meio de comunicação e um conhecimento necessário. Ela assim significa, no entanto, porque ligada a sentidos próprios à língua nacional que, enquanto unidade político-simbólica de um país, representa-se como um sistema totalizante pelo caráter material do sentido e pressupõe respeito à norma gramatical no âmbito da escrita vide a tradição escolar, assim reproduzindo-se também no imaginário da fala.

Marco de valorização social de um modo de expressão legítimo, a língua nacional como saber necessário responsabiliza o sujeito (cf. Pfeiffer, 2002), o que na mídia mercantiliza-se como o bom uso, a boa compreensão, e faz da língua uma relação termo-a-termo com o pensamento em uma ótica purificadora e idealista, como se tudo pudesse ser dito bastando evocar um poder criador inscrito na língua e no sujeito. Este é um processo que se encena sem equívocos e de modo tão imediatista como qualquer outro que põe em relação conhecimento e objeto no mercado de informações. Sobretudo, porque se produz como se os sentidos existissem em si mesmos, em relação transparente com a literalidade do significante (Pêcheux, 1995).

\footnotetext{
* Este artigo apresenta nossa dissertação de mestrado, a qual deu vazão ao projeto de tese intitulado Minha Lingua, Patrimônio Nosso, ligado à Linha de Pesquisa Língua, Sujeito e História.

** Doutoranda em Letras - Estudos Linguísticos, no PPGL/UFSM, sob orientação da Prof. ${ }^{a}$ Dr. Amanda Eloina Scherer. Bolsista Capes. E-mail: laricervo@yahoo.com.br
} 
Partindo desses pressupostos, para nossa reflexão acerca da língua como objeto de divulgação no/pelo dizer de linguistas, trabalhamos com textos publicados por Mattoso Câmara, em A Cigarra Magazine, nos anos 50, em paralelo com textos de José Luiz Fiorin, em Lingua Portuguesa, dos anos 2000. O trajeto que percorremos para tal reflexão teve como procedimento metodológico a própria leitura de arquivo, proposta por Pêcheux (1997). Trabalhando com sequências discursivas que emergiram nas/pelas condições de produção do decorrer da pesquisa, constituímos um corpus representativo de nossa tentativa de explicitar regularidades discursivas inscritas em textualidades distintas dentro da mesma ordem, que é a do discurso de divulgação científica. Por isso, os domínios de análise partiram do modo de organização da textualidade em si, para observarmos como os linguistas significam na posição-sujeito divulgador, até os vestígios próprios à significação da língua como objeto de divulgação.

Nosso primeiro periódico a ser problematizado foi $A$ Cigarra, revista lançada em 1914 e que, ao longo dos anos, foi especializando-se em consonância aos interesses de um público predominantemente feminino. Nos anos 50, em meio a grande maioria dos textos sobre moda, elegância, comportamento, culinária, etc., Mattoso Câmara noticiou a publicação de quatorze obras sobre os estudos da língua e da linguagem, em particular estudos filológicos, do português e alfabetização indígena (cf. Uchôa, 2000), dirigindo-se especialmente aos pares, professores universitários, e aos professores do ensino secundário. Esta era a seção Livros, duas páginas destinadas à crítica de obras literárias por especialistas. Ao todo, foram publicadas doze resenhas críticas por Mattoso Câmara entre os anos de 1957 e $1960^{1}$ n'A Cigarra.

O segundo, a Lingua Portuguesa, em contraste às condições de produção de $A$ Cigarra Magaz̧ine, representa um momento de alta especialização das tecnologias da informação quanto aos recursos gráficoeditoriais e à proposta de um periódico de vulgarização do conhecimento voltado à língua propriamente. Veiculada por uma editora ligada à oferta de 'soluções' para organizações em geral, a Lingua Portuguesa é um periódico pluridisciplinar cujo objeto língua é sugerido em sua relação de unidade $\mathrm{x}$ diversidade e em uma condição de ferramenta de comunicação para a boa expressão oral e escrita, para a garantia de cidadania e, especialmente, para o

\footnotetext{
1 Para a realização da dissertação, encontramos apenas cinco textos de Mattoso Câmara do total dos doze publicados em A Cigarra Magazine. Dois deles foram por nós fotografados no Museu de Comunicação Social Hipólito José da Costa, de Porto Alegre/RS. Os outros três proveram do acervo da Fundação Biblioteca Nacional, do Rio de Janeiro/RJ, tendo sido gentilmente cedidos por Tatiana Freire de Moura, Mestre pela Universidade Federal Fluminense (UFF), sob a orientação da Prof. ${ }^{a}$ Dr. Bethania Mariani.
} 
aperfeiçoamento e o sucesso profissional. José Luiz Fiorin, nesse contexto, publica(va) artigos em praticamente todos os exemplares, em seções variadas.

A autoria dos textos por linguistas, nesse processo, despertou nosso interesse pela possibilidade de problematizarmos a participação de sujeitos que assumem em um dado momento a posição-sujeito divulgadores em cotejo à sua significação enquanto sujeitos da ciência, portanto, comprometidos com uma certa ordem de discurso e, ao mesmo tempo, com instituições e com o modo como elas administram o conhecimento (cf. Orlandi, 2006). Daí uma prática que joga com o objeto de conhecimento enquanto objeto de divulgação para além do meio científico-acadêmico, o que faz os linguistas (re)interpretarem problematizando seu modo próprio de significação na posição-sujeito da ciência.

Em um primeiro momento, a análise mostrou-nos que, na posição de divulgadores, os linguistas comentam ciência sem estarem presos à cópia, à repetição. Isso significa que a textualização do discurso é uma prática de escrita a partir de uma maturidade teórica, de uma relação tal com o interdiscurso que os permite singularizar pelo gesto de interpretação, no jogo com a dispersão, com a variança (cf. Orlandi, 2001). Os mecanismos de produção que encenam a versão de ciência em que se constitui o discurso de divulgação científica, como a ausência de fundamentações teóricas, são, portanto, efeitos apenas na superfície material dos textos, pois ao divulgarem os linguistas escrevem sem se desidentificarem da posição-sujeito da ciência.

É também por não se (des)identificarem que, em um segundo momento, entendemos que é um modo de significação político nessa posição que se reflete na posição divulgador e que abre caminho para os vestígios sobre a língua. Quando da problematização dos textos de Mattoso Câmara, observamos em nosso corpus uma regularidade discursiva quanto à temática das obras noticiadas, a saber, uma normatividade que estrutura a língua enquanto um sistema de regras e que prevê adequações de uso oral e escrito, reflexos de um saber gramatical em diferentes tradições.

Próprias para o ensino superior e secundário, as obras resenhadas por Mattoso Câmara representam o mercado escolar e, ao mesmo tempo, o mercado, na época, da gramatização (cf. Orlandi, 2002). Mas, por outro lado, aquele era um momento de tensão devido à instauração da NGB (Nomenclatura Gramatical Brasileira), momento esse do qual o linguista valeuse mesmo que em uma revista feminina, porque comprometido com o processo de legitimação da linguística como ciência e disciplina acadêmica no Brasil e, ao mesmo tempo, empenhado em prol do reconhecimento próprio enquanto profissional das ciências da linguagem. Por isso, ele produzia as notícias críticas oferecendo veementes elogios aos autores das obras, seus pares que mereciam seu respeito, e elogios exacerbados quanto ao desenvolvimento das obras em si, mas, em contrapartida, também correções e críticas 
expressivas às obras em particular pelo que objetivavam ou pela linha teórica a que se filiavam.

Quando da problematização dos textos de José Luiz Fiorin, observamos a regularidade do trabalho do linguista frente às possibilidades de variação em uma mesma língua e de hierarquia entre línguas, em combate a preconceitos linguísticos, bem como frente a um poder criador da língua enquanto condição para a nomeação do real e do imaginário. Para além de uma preocupação com o aperfeiçoamento profissional e empresarial a que se propõe a revista, como um linguista Fiorin está propondo uma desmistificação da língua imaginária (Ibid.) como única significação de língua e, junto a esse conhecimento linguístico voltado para a tolerância e democracia, uma atenção à língua enquanto meio possível de toda e qualquer interação e criação de sentidos, o que se inscreve em um projeto de socialização da ciência.

Se um preocupa-se em fazer reconhecer a si mesmo e em legitimar uma ciência e uma disciplina no território brasileiro, o outro, no mesmo processo discursivo, preocupa-se em esclarecer essa ciência, o que é um sinal de que no imaginário coletivo ainda predominam certas crenças sobre o que é língua e o saber sobre ela, as quais precisam ser pelo menos questionadas. Estamos, agora, tocando novamente no já-lá recorrente da língua nacional, cujo traço da ideologia reproduz-se em uma desigualdade estruturante posta em circulação pelo mercado escolar. Uma língua cujo conhecimento favorece a clareza e a precisão, garantindo a eficácia em termos retórico-comunicacionais, o que Orlandi (Ibid.) relata-nos como recorrente no mercado da língua desde os primórdios das práticas de divulgação no Brasil.

Referendarmos essa tradição na língua pode até parecer lugar-comum, entretanto ela é o fulcro do trabalho dos linguistas como divulgadores. Afinal, ao realizarem um serviço de 'publicização', nesse caso, eles estão negociando uma integração, perturbando a estabilização parafrástica, como diria Pêcheux (1999) para falar da memória, porque produzem o discurso em um movimento de alerta e de denúncia de que por trás do senso comum da língua há um objeto de tratamento científico que muito pode contribuir para a sociedade, bem como não se resume a uma estrutura de regras.

Estamos diante, então, de uma disputa de interpretações que, ao desestabilizar pelo movimento de deriva dos sentidos, representa tensão frente ao já instituído. Contudo, ela não provoca (des)regulamentação. Primeiro, porque tanto Mattoso Câmara quanto José Luiz Fiorin são divulgadores terceirizados para os periódicos, daí um ponto de regularidade instável no processo discursivo. Não obstante, porque questionando a supremacia do saber sobre a língua nacional, os linguistas estão confrontando toda uma representação simbólica enraizada tanto em políticas de língua (cf. Orlandi, 2002) quanto em política de ciência (cf. Guimarães, 2001, 2003). 
A tensão, desse modo, confronta uma conjuntura sócio-histórica, uma forma histórica de significação de sociedade e sujeito na relação com o jurídico. Daí que, em não deslocando, pelo menos questiona. Mas se língua é, para o Estado, garantia de unidade, significação essa que ressoa na própria história das ideias linguísticas e que a mídia reproduz de algum modo em seus veículos de comunicação, há que se questionar a linguística em si em seu estatuto de ciência. A divisão constitutiva enquanto uma ciência da língua e das línguas, como referem Gadet e Pêcheux (2004), é um sintoma que permite sucumbir o real da língua aos atos de linguagem. Mas, afinal, até que ponto essa ciência se permite pensar no que lhe é próprio sem se apoiar no logicamente estabilizado e recair em armadilha de visão reducionista? Até que ponto é preciso a ela confrontar esse resíduo do saber no tocante ao mercado escolar e ao mercado de divulgação?

A linguística como ciência e suas relações com políticas públicas é, para nós, a mote pelo qual os linguistas propõem um algo mais em um meio midiático cujo funcionamento, pela mercantilização, pode acabar recaindo no mesmo ideal de uma língua ferramenta e norma. Assim é que a posição assumida pelos linguistas não deixa de ser uma posição de mercantilizadores. Contudo, se é interessante à mídia a formação imaginária do linguista como aquele que tem o conhecimento da língua de modo a administrar a sua significação no social (cf. Orlandi, 2002), por outro lado, a mercantilização não faz de ambos sujeitos a serviço de esclarecimentos e purificações. É por isso que Mattoso Câmara e José Luiz Fiorin figuraram, neste trabalho, em detrimento de tantos outros linguistas que produzem textos para periódicos de mídia, representando a possibilidade de, no jogo do dizer, mostrar que o político (cf. Orlandi, 1998) também é espaço de resistência.

Nesse processo, vimos, então, que o que é pretexto significa invariavelmente como produto, uma informação que o sujeito adquire para algum fim, o da comunicação. E, para nós, nunca é demais voltarmo-nos ao lugar-comum na significação da língua porque a política do dizer, ao se constituir, ressoa na política do silêncio (cf. Orlandi, 1995), ou seja, naquilo que é dito em detrimento do que não é dito e fica silenciado na margem. E é este recorte no sentido, que recebe visibilidade na/pela mídia, circula no social constituindo as "coisas a saber" (cf. Pêcheux, 1999), tecendo a trama das relações cotidianas do sujeito com o conhecimento. Com tudo isso, o que observamos é que essa relação entre ciência, Estado e tecnologias da informação inscreve-se num processo discursivo cujo sentido predominante é, no dizer de Pêcheux (1990, p.11), uma "maneira política de negar a política". 


\section{Referências}

GADET, Françoise; PÊCHEUX, Michel. A língua inatingível. Traduzido por B. Mariani; M. E. C. de Mello. Campinas: Pontes, 2004. p.19-26.

GUIMARÃES, Eduardo. A ciência entre as políticas científicas e a mídia. In:

(org.). Produção e circulação do conhecimento. Estado, Mídia, Sociedade. Campinas: Pontes: 2001.

Política científica e produção de conhecimento no Brasil (Uma aliança tecnológica?). In: (org.). Produção e circulação do conhecimento. Política, Ciência, Divulgação. Campinas: Pontes: 2003. 2.v.

ORLANDI, Eni P. As formas do silêncio: no movimento dos sentidos. 3.ed. Campinas: Unicamp, 1995.

2001.

Discurso e texto: formação e circulação dos sentidos. Campinas: Fontes,

. Língua e conhecimento lingüístico: para uma história das idéias no Brasil. São Paulo: Cortez, 2002.

Apresentação. Um fato, um acontecimento, uma história: idéias lingüísticas no

Brasil. Relatos, n.6. Disponível em: <http://www.unicamp.br/iel/hil/publica/relatos_06.html>. Acesso em: 26.jan.06.

PÊCHEUX, Michel. Delimitações, inversões e deslocamentos. Traduzido por J. H. Nunes. Caderno de Estudos Lingüísticos, Campinas, 19: 7-24, jul.-dez.1990.

. Semântica e Discurso: uma crítica à afirmação do óbvio. 2.ed. Traduzido por E. P. Orlandi [et.al.]. Campinas: Fontes, 1995. p.87-94; 159-238.

. Ler o Arquivo Hoje. Traduzido por M.G.L.M. do Amaral. In: ORLANDI, Eni P. (org.) [et.al.]. Gestos de leitura. Da História no Discurso. 2.ed. Campinas: Unicamp, 1997.

Papel da memória. In: ACHARD, Pierre [et.al.]. Papel da memória. Traduzido por J.H.Nunes. Campinas: Pontes, 1999.

PFEIFFER, Claudia C. O lugar do Conhecimento na Escola. Alunos e Professores em Busca da Autorização. Escritos, Campinas, 7: 9-20, 2002.

UCHÔA, Carlos Eduardo Falcão. A colaboração de Mattoso Câmara em A Cigarra (1957-1960). Confluência, Rio de Janeiro, n.20, 2000. 